\title{
Enteric methane emission from Jersey cows during the spring transition from indoor feeding to grazing
}

\author{
Marcin Szalanski, ${ }^{1 *}$ Troels Kristensen, ${ }^{2}$ Gareth Difford, ${ }^{1,3}$ Jan Lassen, ${ }^{1,4}$ Albert J. Buitenhuis, ${ }^{1}$ \\ Marcin Pszczola, ${ }^{5}$ and Peter Løvendahl ${ }^{1}$ \\ ${ }^{1}$ QGG-MBG, Dept. Molecular Biology and Genetics, Aarhus University, AU-Foulum, DK-8830 Tjele, Denmark \\ ${ }^{2}$ AGRO, Dept. Agroecology, Aarhus University, AU-Foulum, DK-8830 Tjele, Denmark \\ ${ }^{3}$ Wageningen University \& Research Animal Breeding and Genomics, $6700 \mathrm{AH}$ Wageningen, the Netherlands \\ ${ }^{4}$ Viking Genetics, Ebeltoftvej 16, 8960 Randers, Denmark \\ ${ }^{5}$ Department of Genetics and Animal Breeding, University of Life Sciences in Poznan, Wołyńska 33, 60-637 Poznań, Poland
}

\section{ABSTRACT}

Organic dairy cows in Denmark are often kept indoors during the winter and outside at least part time in the summer. Consequently, their diet changes by the season. We hypothesized that grazing might affect enteric $\mathrm{CH}_{4}$ emissions due to changes in the nutrition, maintenance, and activity of the cows, and they might differentially respond to these factors. This study assessed the repeatability of enteric $\mathrm{CH}_{4}$ emission measurements for Jersey cattle in a commercial organic dairy herd in Denmark. It also evaluated the effects of a gradual transition from indoor winter feeding to outdoor spring grazing. Further, it assessed the individual-level correlations between measurements during the consecutive feeding periods (phenotype $\times$ environment, $\mathrm{P} \times \mathrm{E}$ ) as neither pedigrees nor genotypes were available to estimate a genotype by environment effect. Ninety-six mixed-parity lactating Jersey cows were monitored for $30 \mathrm{~d}$ before grazing and for $24 \mathrm{~d}$ while grazing. The cows spent 8 to $11 \mathrm{~h}$ grazing each day and had free access to an in-barn automatic milking system (AMS). For each visit to the AMS, milk yield was recorded and logged along with date and time. Monitoring equipment installed in the AMS feed bins continuously measured enteric $\mathrm{CH}_{4}$ and $\mathrm{CO}_{2}$ concentrations (ppm) using a noninvasive "sniffer" method. Raw enteric $\mathrm{CH}_{4}$ and $\mathrm{CO}_{2}$ concentrations and their ratio $\left(\mathrm{CH}_{4}: \mathrm{CO}_{2}\right)$ were derived from average concentrations measured during milking and per day for each cow. We used mixed models equations to estimate variance components and adjust for the fixed and random effects influencing the analyzed gas concentrations. Univariate models were used to precorrect the gas measurements for diurnal variation and to estimate the direct effect of grazing on the ana-

Received November 13, 2018.

Accepted March 15, 2019.

*Corresponding author: mszalans@mbg.au.dk lyzed concentrations. A bivariate model was used to assess the correlation between the 2 periods (in-barn vs. grazing) for each gas concentration. Grazing had a weak $\mathrm{P} \times \mathrm{E}$ interaction for daily average $\mathrm{CH}_{4}$ and $\mathrm{CO}_{2}$ gas concentrations. Bivariate repeatability estimates for average $\mathrm{CH}_{4}$ and $\mathrm{CO}_{2}$ concentrations and $\mathrm{CH}_{4}: \mathrm{CO}_{2}$ were 0.77 to $0.78,0.73$ to 0.80 , and 0.26 , respectively. Repeatability for $\mathrm{CH}_{4}: \mathrm{CO}_{2}$ was low $(0.26)$ but indicated some between-animal variation. In conclusion, grazing does not create significant shifts compared with indoor feeding in how animals rank for average $\mathrm{CH}_{4}$ and $\mathrm{CO}_{2}$ concentrations and $\mathrm{CH}_{4}: \mathrm{CO}_{2}$. We found no evidence that separate evaluation is needed to quantify enteric $\mathrm{CH}_{4}$ and $\mathrm{CO}_{2}$ emissions from Jersey cows during inbarn and grazing periods.

Key words: methane, grazing, genotype by environment interaction, dairy, Jersey

\section{INTRODUCTION}

Because enteric methane $\left(\mathrm{CH}_{4}\right)$ emissions of ruminants compose a large proportion of greenhouse gas (GHG) from the agricultural sector, various mitigation strategies (Steinfeld et al., 2006; Hammond et al., 2016a) and phenotypes for identifying and selecting cattle with lower emissions have been proposed (de Haas et al., 2017). Mitigation of enteric $\mathrm{CH}_{4}$ emissions from ruminants may be achieved by the intensification of production, improved efficiency of feed conversion, feed additives, improved genetics, better manure management, and biogas production (Steinfeld et al., 2006). Recent studies found individual and genetic variation in $\mathrm{CH}_{4}$ emission traits, including $\mathrm{CH}_{4}$ concentration and $\mathrm{CH}_{4}: \mathrm{CO}_{2}$ ratio, measured using noninvasive methods in Holstein cows (e.g., Lassen and Løvendahl, 2016; Pszczola et al., 2017; Zetouni et al., 2018).

Measuring enteric GHG emissions from dairy cattle is also more feasible than from cattle in other production systems. In several proven applications, measur- 
ing systems to analyze GHG concentrations from the breath of cows have been integrated with an automatic milking system (AMS). These applications could provide useful, repeatable information on GHG emissions from dairy cows (e.g., Garnsworthy et al., 2012; Lassen et al., 2012).

Globally, total $\mathrm{CH}_{4}$ production from dairy cattle is lower than from beef cattle (FAO, 2018). This fact has been attributed to more extensive production in the latter, involving various factors such as scattered, small-holder production (dense populated areas, such as India) and nutritional and maintenance differences (large commercial beef producers, such as Brazil). However, in Western European countries, such as Denmark, most enteric $\mathrm{CH}_{4}$ is produced by dairy cattle (FAO, 2018). Thus, evaluating enteric $\mathrm{CH}_{4}$ emissions from dairy cattle is important to develop mitigation strategies in these countries.

In some countries, such as Denmark, large numbers of organic dairy cattle and some conventional dairy cattle are placed in pastures during the spring and summer months. The change in diet from indoor partial mixed rations (PMR) to grazing might increase $\mathrm{CH}_{4}$ production because the forage to concentrate ratio usually increases $\mathrm{CH}_{4}$ emissions (Aguerre et al., 2011). Methane emission is highly dependent on the source of fiber in the diet (Hammond et al., 2016b), which determines variation in VFA profile (Dijkstra et al., 2012). The effects of grazing and dietary changes in the forage to concentrate ratio on $\mathrm{CH}_{4}$ emissions are well established for dairy cattle, but limited knowledge exists on the effects of ranking cows by $\mathrm{CH}_{4}$ emissions between indoor feeding versus grazing. Enteric $\mathrm{CH}_{4}$ emission studies have mostly been conducted in either solely indoor (e.g., Garnsworthy et al., 2012) or grazing (e.g., Hammond et al., 2015) systems. Few studies have been conducted in a combined indoor-grazing system to compare the effect of grazing on enteric $\mathrm{CH}_{4}$ emission with that of indoor handling (e.g., Eckert et al., 2018).

Potential genotype by environment $(\mathbf{G} \times \mathbf{E})$ (diet) interactions are of wider relevance to genetic analyses. To estimate genetic correlations to infer the $\mathrm{G} \times \mathrm{E}$ effect accurately, measurements of $\mathrm{CH}_{4}$ from thousands of related individuals are required under the environmental conditions in which the animals are expected to perform (Falconer and Mackay, 1996; Bijma and Bastiaansen, 2014).

Individual-level correlations (also called repeatedmeasure correlations) are controlled for nongenetic factors, such as parity or the stage of lactation. This approach can be used to assess potential phenotype $\times$ environment $(\mathbf{P} \times \mathbf{E})$ interactions (Adolph and
Hardin, 2007; Dingemanse and Dochtermann, 2013; Bakdash and Marusich, 2017). Such interactions were found, for example, by Robertson and Waghorn (2002) between different diets for dairy cattle.

We hypothesized that grazing might influence $\mathrm{CH}_{4}$ emissions. To verify our hypothesis, we investigated the potential changes in ranking (individual-level correlations) of animals between the in-barn and grazing periods. First, we assessed the repeatability of $\mathrm{CH}_{4}$ emission collected during in-barn and grazing periods. Second, we investigated the effect of grazing on $\mathrm{CH}_{4}$ emission. Third, we investigated if individual animals perform similarly in 2 different environments $(\mathrm{P} \times \mathrm{E})$.

\section{MATERIALS AND METHODS}

\section{Ethical Statement}

The animal experimental procedure was performed according to a protocol approved by the Animal Experiments Inspectorate, Danish Veterinary and Food Administration, Ministry of Environment and Food of Denmark (approval number 2016-15-0201-00959).

\section{Data}

In this study, we used a herd of Danish Jersey cows kept on an organic commercial farm in Denmark. The cows were in parities of 1 to 8 and ranged from 1 to 829 DIM. Forty-nine cows were within the first parity and 109 cows in higher parities. The experiment lasted $53 \mathrm{~d}$, starting on April 7, 2016, and ending on May 30, 2016. Three AMS units were available on the farm. All AMS units were used for the same group of 158 cows.

The cows were released to the pasture for the first time on May 7, 2016. Data were recorded for $30 \mathrm{~d}$ during the nongrazing period before release, with data being recorded for $24 \mathrm{~d}$ following release. Animals spent an increasing amount of hours on pasture each day. The DMI was seen as herd-level information. In total, DMI came from 3 sources: PMR, AMS concentrate feed, and pasture. Partial mixed rations (fresh weight) consisted of horsebean (3\% during indoor period, $2 \%$ during grazing), $32 \%$ protein concentrate $(2 \%$ during indoor period, $3 \%$ during grazing), wheat grain (9\% during indoor period, $0 \%$ during grazing), rye grain (6\% during indoor period, $25 \%$ during grazing), mineral mix (1\% during indoor period, $2 \%$ during grazing), straw (1\% in both periods), alfalfa silage (3\% during indoor period, $5 \%$ during grazing), pea silage ( $12 \%$ during indoor period, $0 \%$ during grazing), and clover grass silage $(63 \%$ during indoor period, $61 \%$ during grazing). The AMS concentrate composition was the same in both periods. 
The AMS concentrate feed (fresh weight) consisted of $32 \%$ protein concentrate $(63 \%)$ and barley grain $(37 \%)$. Pasture feed (fresh weight) consisted of $83 \%$ grass, $5 \%$ white clover, and $12 \%$ other (no nutrient analysis information available). The average DMI of the PMR and AMS concentrate feed of the herd was measured daily during the indoor period, and pasture intake DMI was estimated daily assuming the same daily total herd DMI as the average of the indoor period (Figure 1). Such estimation assumes that herd total daily DMI stays at the same level during whole grazing period. Lack of variation in herd total daily DMI can affect pasture daily DMI estimates and therefore model solutions. However, herd-level DMI was the only information available on animals' DMI during grazing period, and it proved to be important part of explaining the variation in gas emissions in bivariate models.

Milking time frames and milk yield data were available from AMS units. However, milk yield data could not be used because some milkings were discarded during data filtering and editing.

\section{Gas Measurements}

Methane and $\mathrm{CO}_{2}$ concentrations were measured continuously each second by nondispersive infrared analyzers (Guardian NG/Gascard, Edinburgh Instruments Ltd., Livingston, UK) and transformed to ppm units. Two types of analyzers were used, one for $\mathrm{CH}_{4}$ and one for $\mathrm{CO}_{2}$, to measure each gas separately. The gas sampling inlets were installed in the feed bin of each AMS (DeLaval International AB, Tumba, Sweden) unit placed in the barn. The data from the analyzers were logged using Novus Field Logger software (Novus Automation, Guajuviras, Brazil). This type of setup is referred to as a "sniffer" (Garnsworthy et al., 2012). In total, the measuring setup consisted of 1 air inlet, 2 analyzers, and 1 logger per AMS unit.

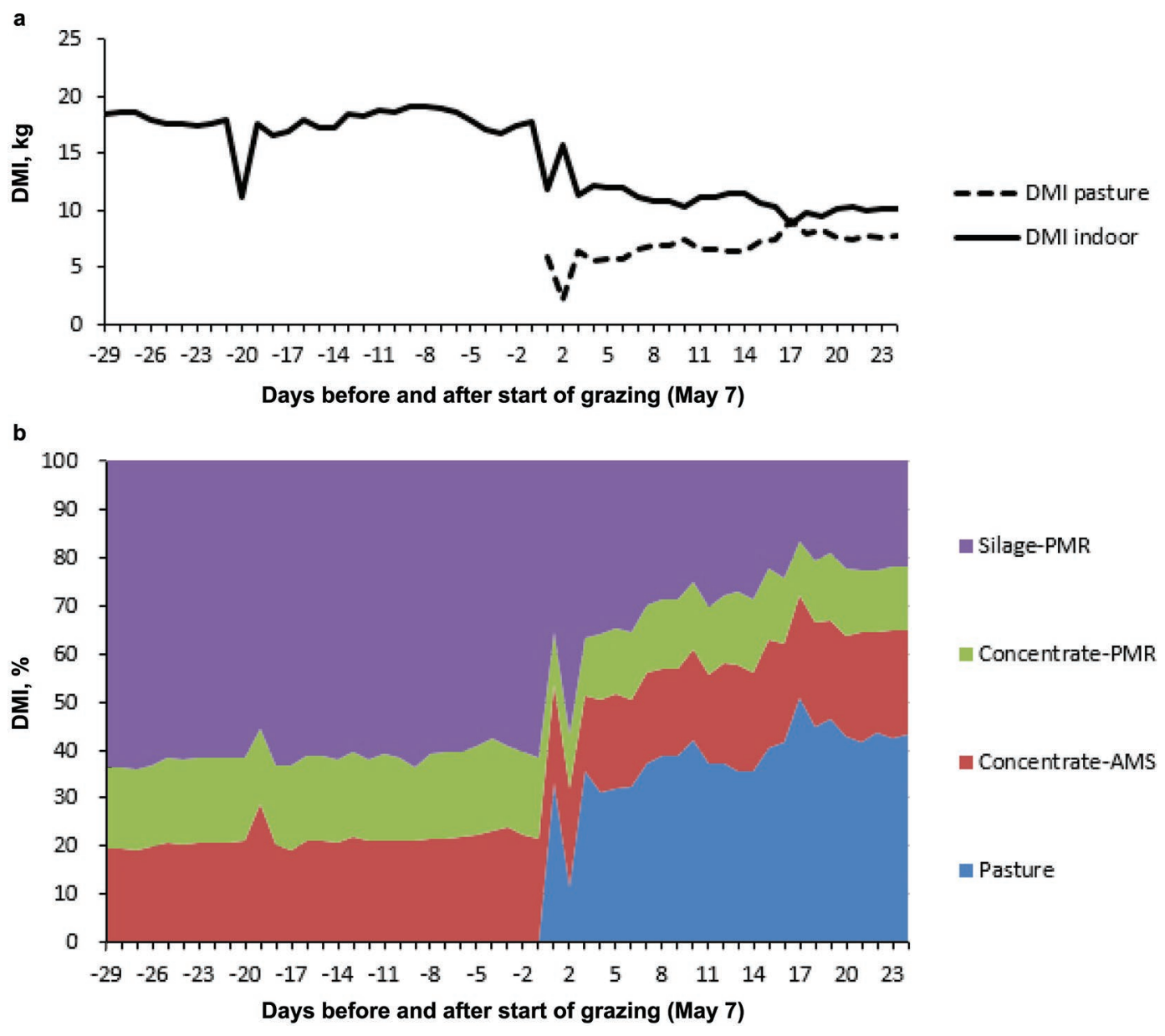

Figure 1. Dry matter intake (a; $\mathrm{kg}$ of DM/cow per day) and diet composition (b; \% of DMI) indoors and at pasture in the transition period based on the average lactation of cows in a Jersey herd. PMR = partial mixed ration; AMS = automatic milking system. 


\section{Data Filtering and Editing}

Data from 2 of the 3 AMS units installed within 1 technological group were used in the study; the third sniffer installation malfunctioned. The technological group refers to a group of animals supplied with a specific feed composition. Gas concentrations (ppm) were measured during milking. Slightly over $12 \%$ of the average $\mathrm{CH}_{4}$ concentrations from individual milkings from the remaining 2 sniffers were negative. The reason for this problem was not identified, but random sniffer malfunction was likely. The negative data were excluded from all subsequent analyses. Some milkings were removed because their duration was too short (less than $200 \mathrm{~s}$ ), they were incomplete, or they lacked time alignment with AMS data. Cows with fewer than 3 records averaged per day and per AMS unit were removed from the database. Each cow needed at least 3 records in each period (in-barn and grazing), with a minimum of 6 records per cow being required. In addition, only animals with a DIM between 5 and 305 were retained in the database. This approach was used to represent standard lactation. Finally, after data filtering, gas concentration measurements for 96 of the 158 cows were left in the database. As a result, an average of 60 (SD 18) daily and AMS unit averaged concentrations were measured for each cow. Only these data were used later in all analyses.

The data from the sniffers were precorrected in 4 steps. In step 1, the data from the AMS and sniffer were synchronized. The clocks in the AMS and logger devices were not synchronized at the start of the measuring period; therefore, data from AMS containing information about cows and milking times were initially not aligned with data from the sniffer. The data from the 2 systems were time aligned using an algorithm based on exponential smoothing, as proposed by Difford et al. (2016). In step 2, gas concentrations $\left(\mathrm{CH}_{4}\right.$ and $\left.\mathrm{CO}_{2}\right)$ and their ratio $\left(\mathrm{CH}_{4}: \mathrm{CO}_{2}\right)$ were averaged within each milking; gas concentrations were not corrected for background gas concentrations. In step 3, the averages obtained for milkings were precorrected for diurnal variation (within day variation) using the Fourier series approach, as proposed in Løvendahl and Bjerring (2006). The precorrection model was as follows:

$$
y_{i j}=\beta_{0}+\sum_{j=1}^{5}\left[f_{1 j} \sin (2 \pi j \theta)+f_{2 j} \cos (2 \pi j \theta)\right]+\mathrm{Cow}_{i}+e_{i j},
$$

where $y_{i j}$ is the gas concentrations in ppm units $\left(\mathrm{CH}_{4}\right.$, $\mathrm{CO}_{2}$, or $\mathrm{CH}_{4}: \mathrm{CO}_{2}$ ) averaged per milking for each cow, $\beta_{0}$ is the intercept, animal $\left(\mathrm{Cow}_{i}\right)$ is a random effect of the $i$ th animal, and $e_{i j}$ is a random residual. Terms $f_{1 j}$ and $f_{2 j}$ are fixed regression coefficients of the $j$ th $(j=$ $1, \ldots, 5)$ harmonics of Fourier series approach (similar to that used by Løvendahl and Bjerring, 2006), where $\theta$ denotes the fractional time of a day. This fraction is represented by the number of seconds that have passed after $2400 \mathrm{~h}$ (midnight) divided by the total number of seconds within a day.

The precorrection model was intended to correct the milking averaged concentrations for diurnal variation before they were averaged over days. Fourier series regression coefficients were extracted from the model output and subtracted from the averaged concentrations of the milkings. Next, the Fourier series regression coefficients were multiplied by the $\pi$ value, which represents the number of radians from $1200 \mathrm{~h}$ (midday), representing the half fraction of the day. Afterward, correction terms were added to the milking averaged concentrations. This precorrection resulted in milking averaged concentrations centered to $1200 \mathrm{~h}$, which were free of the effects of diurnal variation in gas emissions. In step 4, a weighted average based on the length of visit recording was taken on the precorrected milking averaged concentrations for each cow within each day and within the AMS unit. Each cow could have milkings of different duration; therefore, the daily averaged concentrations were adjusted for the average milking duration for each cow on certain days and for certain AMS units (time-weighted average).

\section{Statistical Analysis}

The precorrected daily averaged concentrations were used as the response variable in a linear univariate mixed model using the MIXED procedure of SAS software (version 9.3, SAS Institute Inc., Cary, NC), which was employed to estimate the direct effect of grazing on gas emissions by placing grazing as a class effect with 2 levels (in-barn or grazing). Least squares means for each of measuring periods (no grazing and grazing) were estimated using LSMEANS statement of MIXED procedure of the SAS software. The same univariate model was used for each concentration $\left(\mathrm{CH}_{4}, \mathrm{CO}_{2}\right.$, or $\mathrm{CH}_{4}: \mathrm{CO}_{2}$, respectively) separately, producing 3 separate models that differed by dependent variable only. The univariate model was as follows:

$$
\begin{aligned}
y_{i j k l} & =\beta_{0}+\operatorname{Grazing}_{j}+\operatorname{RobotID}_{k}+\beta_{1} \mathrm{DIM}+\beta_{2} e^{-0.05 \times \mathrm{DIM}} \\
& + \text { Parity }_{l}+\mathrm{Cow}_{i}+e_{i j k l},
\end{aligned}
$$


where $y_{i j k l}$ is the daily averaged gas concentration (ppm; $\mathrm{CH}_{4}, \mathrm{CO}_{2}$, or $\mathrm{CH}_{4}: \mathrm{CO}_{2}$, respectively), $\beta_{0}$ is the intercept, Parity is the fixed effect of the $l$ th parity $(l=1$, $\ldots, 8)$, Grazing is the fixed effect of the $j$ th grazing period ( $j=$ in-barn or grazing), RobotID is a fixed effect of the $k$ th robot $(k=1,2)$, DIM is a covariate of days in milk (DIM $=5, \ldots, 305)$ modeled as a Wilmink function (Wilmink, 1987) with $\beta_{1}, \beta_{2}$ as the regression coefficients of DIM, Cow is the random cow effect of the $i$ th cow $(i=1, \ldots, 96) \sim N\left(0, \sigma_{c}^{2}\right)$, and $e_{i j k l}$ is the random error on the ijklth daily averaged gas concentration $\sim N\left(0, \sigma_{e}^{2}\right)$.

\section{Grazing Versus Nongrazing}

Bivariate statistical analysis was performed using DMU software (Madsen and Jensen, 2013). The data set containing daily gas concentrations was divided into 2 periods (in-barn and grazing) to estimate the correlation between the grazing and nongrazing period, as well as differences in repeatability estimates between the periods. All average daily gas concentrations were split into 2 sets, during the nongrazing and grazing periods, respectively. A bivariate mixed model approach was used in the analysis. Similar to the univariate analysis, the same model was used for each average daily gas concentration and their ratio separately, resulting in 3 separate models that only differed by the dependent variable. Daily averaged values and the regression lines of gas concentrations and their ratio per each robot are presented in Figure 2. The bivariate model was as follows:

$$
\begin{aligned}
y_{t i j k}= & \beta_{0 t}+\operatorname{RobotID}_{t j}+\beta_{1} \operatorname{DIM}_{t}+\beta_{2} e^{-0.05 \times \operatorname{DIM}_{t}} \\
& +\operatorname{Parity}_{t k}+\beta_{3} \mathrm{DMI}_{t}+\mathrm{Cow}_{t i}+e_{t i j k}
\end{aligned}
$$

where $y_{t i j k}$ is the daily averaged gas concentrations (ppm; $\mathrm{CH}_{4}, \mathrm{CO}_{2}$, or $\mathrm{CH}_{4}: \mathrm{CO}_{2}$, respectively) for the th period ( $t=$ in-barn or grazing), $\beta_{0 t}$ is the intercept for the th period, RobotID is a fixed effect of the $j$ th robot $(j=1,2)$, Parity is the fixed effect of the $k$ th parity $(k$ $=1, \ldots, 8)$, DIM is a covariate of days in milk (DIM = $5, \ldots, 305)$ in the th period modeled as a Wilmink function (Wilmink, 1987) with $\beta_{1}$ and $\beta_{2}$ as the regression coefficients of DIM, $\beta_{3}$ is the regression coefficient on daily DMI on the pasture (indicator of whole herdlevel DMI for specific dates), Cow is the random cow effect of the $i$ th cow $(i=1, \ldots, 96) \sim N\left(0, \sigma_{c}^{2}\right)$, and $e_{t j k}$ is the random error on the ijkth daily averaged gas concentration $\sim N\left(0, \sigma_{e}^{2}\right)$. The 2 periods represent separate environments and, as such, between cow covari- ance was defined, while the residual covariance was not defined. Equation [4] shows the variance structure in bivariate models:

$$
\begin{aligned}
& \sigma_{c}^{2}=\mathbf{G}=\operatorname{Var}\left[\begin{array}{l}
c_{t 1} \\
c_{t 2}
\end{array}\right]=\left[\begin{array}{cc}
\sigma_{c t 1}^{2} & \sigma_{c t 1 c t 2} \\
\sigma_{c t 2 c t 1} & \sigma_{c t 2}^{2}
\end{array}\right] \\
& \text { and } \sigma_{e}^{2}=\mathbf{R}=\left[\begin{array}{cc}
\sigma_{e t 1}^{2} & 0 \\
0 & \sigma_{\text {et } 2}^{2}
\end{array}\right],
\end{aligned}
$$

where $\sigma_{c}^{2}$ is the variance of the random cow effect, $\mathbf{G}$ is the variance-covariance matrix for cow, $c_{t 1}$ and $c_{t 2}$ are random cow effect for period 1 (indoor) and period 2 (grazing), respectively, with the variances of the 2 periods being denoted as $\sigma_{c t 1}^{2}$ and $\sigma_{c t 2}^{2}$, respectively, and covariance between periods denoted as $\sigma_{c t 1 c t 2}$ or $\sigma_{c t 2 c t 1}$, respectively; $\sigma_{e}^{2}$ is the random error variance, $\mathbf{R}$ is the residual variance matrix, and $\sigma_{e t 1}^{2}$ and $\sigma_{e t 2}^{2}$ are random error variances for period 1 (indoor) and period 2 (grazing), respectively.

The fixed regression on the DMI covariate was absent in the univariate analysis described in Equation [2] because it would have been confounded with the effect of grazing.

Individual-level correlations (r), were computed as the correlation between random cow solutions using variance components as shown in Equation [5]:

$$
r=\frac{\sigma_{c t 1 c t 2}}{\sqrt{\sigma_{c t 1}^{2}} \times \sqrt{\sigma_{c t 2}^{2}}},
$$

where $r$ is an individual-level correlation coefficient; $\sigma_{c t 1}^{2}$ and $\sigma_{c t 2}^{2}$ are the variances for period 1 representing daily averaged ppm gas concentrations from the indoor period and period 2 representing daily averaged ppm gas concentrations from the grazing period, respectively; and $\sigma_{c t 1 c t 2}$ is the covariance between period 1 (daily averaged gas concentrations from the indoor period) and period 2 (daily averaged gas concentrations from the grazing period), respectively.

\section{Heatmaps}

Heatmaps were created to show the individual correlations (i.e., calculated using Eq. [5]) within and between indoor (nongrazing) and grazing periods. These correlations were used as a measure of ranking. Heatmaps were created using R ( $\mathrm{R}$ Development Core Team, 2008) and DMU (Madsen and Jensen, 2013) software. The data set containing daily averaged gas concentrations $\left(\mathrm{CH}_{4}, \mathrm{CO}_{2}\right.$, or $\mathrm{CH}_{4}: \mathrm{CO}_{2}$, respectively) 

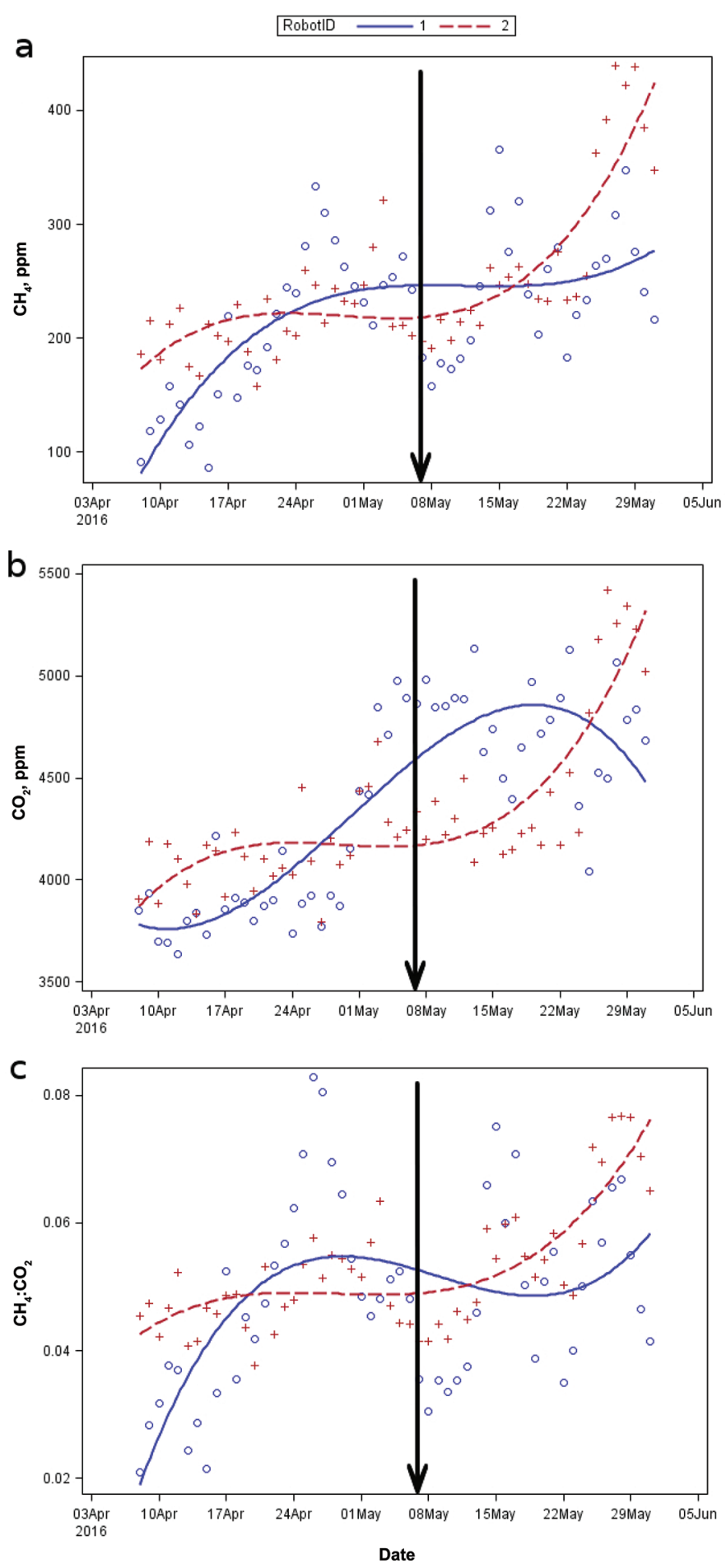

Figure 2. Daily averaged values and the regression lines of gas measurements (ppm) from a Jersey dairy cattle herd: (a) $\mathrm{CH}_{4}$, (b) $\mathrm{CO}_{2}$, and (c) $\mathrm{CH}_{4}: \mathrm{CO}_{2}$. The $\bigcirc$ and + symbols represent daily means from all animals milked in robot number 1 and 2, respectively. The black arrow in each panel indicates the date when the grazing period began (May 7, 2016). was divided into 9 periods, 1 for each week, to check the individual level correlations between all weeks. Weeks were paired with each other. Each pair was put under bivariate analysis, as in Equation [3]. Therefore, daily averaged gas concentrations were analyzed in each pair using the model in Equation [3]. In this case, the dependent variable represented daily averaged gas concentrations from a certain week. Therefore, $t$ subindex represented 2-wk indices (daily averaged gas concentrations from 1-wk vs. daily averaged gas concentrations from another week). After each analysis, the individual level correlation between the 2 analyzed weeks was extracted from the model output. Therefore, each daily averaged gas concentration had correlations for all paired weeks. These correlations formed 3 heatmaps (Figure 3), 1 for each daily averaged gas concentration. Each heatmap was symmetrical, with the diagonal values set at unity.

\section{RESULTS}

\section{Raw Data}

Mean daily $\mathrm{CH}_{4}$ and $\mathrm{CO}_{2}$ concentrations and their ratio were $238.3 \mathrm{ppm}$ (SD 175.7), 4,338.8 ppm (SD 1,152.0), and 0.051 (SD 0.029), respectively (Table 1 ). The values of all daily averaged gas concentrations increased for both the AMS units before the grazing period started (Figure 2).

\section{Univariate Models}

The significance of the influence of grazing on the analyzed daily averaged gas concentrations was estimated using univariate models as described in Equation [2], in which grazing was fitted as a fixed effect. All covariates and effects (except Wilmink function) specified within the univariate model significantly influenced the analyzed daily averaged gas concentrations $(P<0.001)$. Comparison of the differences in the levels of the analyzed daily averaged gas concentrations showed the effect of grazing. The mean daily $\mathrm{CO}_{2}$ was higher for the grazing period than for the indoor period. However, the mean daily $\mathrm{CH}_{4}$ concentration and $\mathrm{CH}_{4}$ : $\mathrm{CO}_{2}$ ratio were lower in the grazing period than in the indoor period (Table 2). The obtained repeatabilities were high, at 0.80 (SE 0.03), 0.73 (SE 0.04), and 0.70 (SE 0.06) for mean daily $\mathrm{CH}_{4}$ and $\mathrm{CO}_{2}$ concentrations and their ratio, respectively (Table 2).

\section{Bivariate Models}

To reveal the potential changes in the ranking of animals between the in-barn and grazing periods, bivariate analyses were performed. Repeatability of mean 


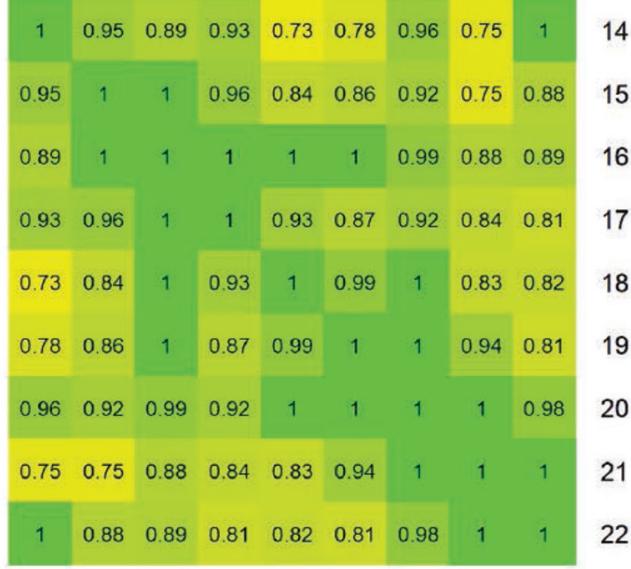

b
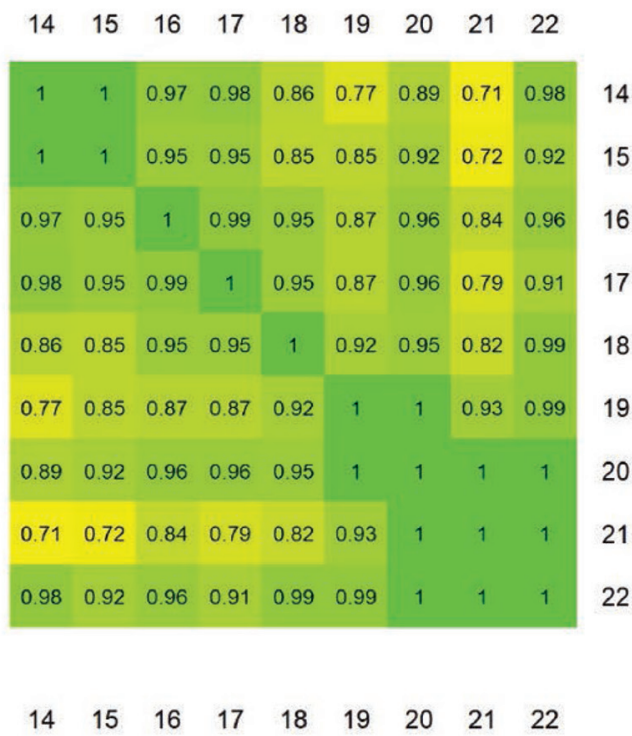

Figure 3. Correlations between weeks for daily averaged $\mathrm{CH}_{4}$ (a) and $\mathrm{CO}_{2}$ (b) gas measurements and $\mathrm{CH}_{4}: \mathrm{CO}_{2}$ ratio (c). Values at the top and side of each heatmap are the number of weeks (ranging from 14 to 22) and follow those indicated in ISO 8601:2004 (ISO, 2004).

The in-barn period was in wk 14 to 17, the grazing period was in wk 19 to 22 , and the transition between the 2 periods occurred in wk 18 .

daily gas ratio from the univariate model was 0.70 (SE 0.06 ) versus 0.26 (SE 0.04 ) within both analyzed periods based on the bivariate model. Repeatability for $\mathrm{CH}_{4}$ and $\mathrm{CO}_{2}$ daily averaged gas concentrations was similar compared with repeatability estimates from the univariate model (Table 2, Table 3). These figures were slightly higher during the indoor (no-grazing) period (Table 3). We estimated very high individual-level correlations between the 2 periods (Table 3 ), which were close to unity at 0.97 to 0.99 , representing the 3 daily averaged gas concentrations $\left(\mathrm{CH}_{4}, \mathrm{CO}_{2}\right.$, and $\left.\mathrm{CH}_{4}: \mathrm{CO}_{2}\right)$.

\section{Heatmaps}

We found that correlations between all weeks for all daily averaged gas concentrations are high and positive (0.65-1.00; Figure 3). However, we obtained higher correlations within single periods (no-grazing period within wk 14-17, grazing period within wk 19-22) than between the 2 periods (wk 14-17 vs. wk 19-22). Week 18 was the transition period between in-barn and grazing periods and was considered as a transition week (Figure 3).

\section{DISCUSSION}

The mean daily emission of $\mathrm{CH}_{4}$ (in ppm units) supported studies on Holstein Friesian cows with similar phenotype and measurement setup (van Engelen et al., 2018, $254 \mathrm{ppm}$ ), but it was lower than in other studies using this type of phenotype and setup (Difford et al., 2016; 890-903 ppm). Possible reasons for these differences could be the breed (Holstein vs. Jersey) or specific effects on the farm, such as wind disturbance, feeding regimen, or diet. Studies on $\mathrm{CH}_{4}$ emission measured directly from the breath in the Jersey breed remain limited to date. Münger and Kreuzer (2008) suggested the absence of persistent $\mathrm{CH}_{4}$ emission differences in 3 breeds of dairy cows (Holstein, Simmental, and Jersey); however, their study used $\mathrm{CH}_{4}$ yield ( $\mathrm{g}$ of $\mathrm{CH}_{4} / \mathrm{kg}$ of DMI) recorded using an intensive respiration chamber method. This approach reduced statistical power due to the small number of animals used, resulting in a small sample size for the analysis. Lassen et al. (2012) found differences between Holstein and Jersey breeds in their $\mathrm{CH}_{4}: \mathrm{CO}_{2}$ concentration ratio measured with a Fourier transform infrared sniffer type device and calculated according to the methodology of Madsen et al. (2010) (g/d units). The mean ratio value from the study of Jersey cows was very similar to the one obtained in the current study, whereas the ratio obtained for the Holstein breed was higher. van Engelen et al. (2018) reported a $\mathrm{CH}_{4}: \mathrm{CO}_{2}$ concentration ratio in Dutch Holstein-Friesians fed PMR indoors, which was up to 
Table 1. Descriptive statistics of daily averaged $\mathrm{CH}_{4}$ and $\mathrm{CO}_{2}$ gas concentrations measured during milking and their ratio

\begin{tabular}{lcccc}
\hline Item & Mean & Minimum & Maximum & SD \\
\hline $\mathrm{CH}_{4}, \mathrm{ppm}$ & 238.3 & 0.1 & $1,740.6$ & 175.7 \\
$\mathrm{CO}_{2}, \mathrm{ppm}$ & $4,338.8$ & $1,467.6$ & $10,661.6$ & $1,152.0$ \\
$\mathrm{CH}_{4}: \mathrm{CO}_{2}$ & 0.051 & 0.000 & 0.264 & 0.029 \\
\hline
\end{tabular}

5 times higher than that reported for Jersey cows in the present study. However, the ratio reported by van Engelen et al. (2018) might have been inflated due to the lower $\mathrm{CO}_{2}$ concentrations reported. The $\mathrm{CO}_{2}$ concentrations obtained in the current study support those obtained by other studies on Holsteins cows fed PMR indoors in the United Kingdom and Denmark (e.g., Bell et al., 2014; Difford et al., 2016). The $\mathrm{CO}_{2}$ emission trait tends to be repeatable (e.g., Lassen et al., 2012; Bell et al., 2014; Difford et al., 2016; Lassen and Løvendahl, 2016). Therefore, factors other than random animal effects must be responsible for differences of such magnitudes, such as the difference between the current study and that of van Engelen et al. (2018). The study by van Engelen et al. (2018) obtained records in the Lely A4 Astronaut (Lely, Maassluis, the Netherlands), which has a more open feeding bin than the Delaval AMS used in our study. One possibility is the dilution of gases due to differences in feed bin dimensions or in environmental factors, such as variable wind speed between installations (Wu et al., 2018).

\section{Univariate Models}

During the grazing period, least squares means daily $\mathrm{CO}_{2}$ emission increased. However, least squares means daily $\mathrm{CH}_{4}$ emission and $\mathrm{CH}_{4}: \mathrm{CO}_{2}$ ratio decreased in the grazing period. The increase in concentrations occurring before the onset of the grazing period and the differences between least squares means suggest that grazing is not responsible for the $\mathrm{CH}_{4}$ emission increase. Sensor drift is likely to be a factor contributing to the increase in gas concentrations because the concentrations were not corrected for background gas concentrations. We expected an increase in $\mathrm{CH}_{4}$ emission during the grazing period because of a change in the composition of dietary fiber (Dijkstra et al., 2012; Hammond et al., 2016b). The negative effect of grazing on $\mathrm{CH}_{4}$ emission can also be explained by chemical composition of pasture forage (Ellis et al., 2012); however, no data on the composition were available in the current study. Thus, the reason of the negative contrast of $\mathrm{CH}_{4}$ emission between indoor and grazing periods remains unknown. Eckert et al. (2018) found no significant difference between mean $\mathrm{CH}_{4}$ emission from PMR (indoors) and PMR + grazing feeding systems in dairy cows, although grazing influenced the daily pattern of $\mathrm{CH}_{4}$ emission in their study. An interaction between the daily $\mathrm{CH}_{4}$ emission pattern and feeding system had a significant influence on emitted $\mathrm{CH}_{4}$. However, both diets were evaluated on different animals, and no animal had records for both diets. Thus, information about the reranking effect of grazing on $\mathrm{CH}_{4}$ emission was not obtained. The $\mathrm{CH}_{4}$ phenotype $(\mathrm{mg} / \mathrm{L})$ of the cows was derived from ppm, which was the phenotype in our study, and the ratio was not reported.

\section{Bivariate Models}

We expected a slight reduction in repeatability for the grazing period after bivariate analysis, considering the change of diet and daily routine for cows, as well as the potentially varying quality of DM from the pasture. Our expectations were only partially confirmed by the results. The comparison of the repeatability values between univariate and bivariate analyses showed no substantial changes in the repeatability for daily averaged $\mathrm{CH}_{4}$ and $\mathrm{CO}_{2}$ concentrations, but a reduced re-

Table 2. Least squares means (SE) and repeatabilities ( $\mathrm{t}$ ) for daily averaged gas concentrations measured during milking representing 2 gas measurements $\left(\mathrm{CH}_{4}, \mathrm{CO}_{2}\right)$, and $\mathrm{CH}_{4}$ : $\mathrm{CO}_{2}$ ratio as output from the univariate models (fixed effects and covariates other than robot and grazing are not shown)

Least squares means (SE)

\begin{tabular}{|c|c|c|c|c|c|}
\hline Trait & Robot 1 & Robot 2 & Indoor & Grazing & $\mathrm{t}(\mathrm{SE})$ \\
\hline $\mathrm{CO}_{2}, \mathrm{ppm}$ & $4,190.8(257.9)$ & $4,262.7(257.7)$ & $4,162.4(257.7)$ & $4,291.2(258.7)^{* * *}$ & $0.73(0.04)$ \\
\hline $\mathrm{CH}_{4}: \mathrm{CO}_{2}$ & $0.044(0.007)$ & $0.049(0.007)$ & $0.050(0.007)$ & $0.042(0.007)^{* * *}$ & $0.70(0.06)$ \\
\hline
\end{tabular}

*** $P<0.001$. 
Table 3. Within-period repeatabilities (t) and individual-level correlations ( $\mathrm{r}$ ) between periods as output from the bivariate models for daily gas concentrations $\left(\mathrm{CH}_{4}, \mathrm{CO}_{2}\right)$ measured during milking, and $\mathrm{CH}_{4}: \mathrm{CO}_{2}$ ratio

\begin{tabular}{llll}
\hline Trait & $\mathrm{t}(\mathrm{SE})_{\text {indoor }}$ & $\mathrm{t}(\mathrm{SE})_{\text {grazing }}$ & \multicolumn{1}{c}{$\mathrm{r}(\mathrm{SE})$} \\
\hline $\mathrm{CH}_{4}$ & $0.78(0.03)$ & $0.77(0.03)$ & $0.99(0.003)$ \\
$\mathrm{CO}_{2}$ & $0.80(0.03)$ & $0.73(0.04)$ & $0.97(0.01)$ \\
$\mathrm{CH}_{4}: \mathrm{CO}_{2}$ & $0.26(0.04)$ & $0.26(0.04)$ & $0.97(0.02)$ \\
\hline
\end{tabular}

peatability for daily averaged gas ratio was found. This finding supported that of van der Laak et al. (2016), who also observed a similar drop during grazing for production traits.

\section{Correlations}

Possible Outcomes. Evaluating the same animals in both periods may result in 3 situations: no change in performance, scaling effect, or $\mathrm{G} \times \mathrm{E}(\mathrm{P} \times \mathrm{E}$ if no genetic information is available). A scaling effect occurs when only the performance among periods, but not the ranking of animals, is affected. Consequently, genotypes are correlated with periods. The $\mathrm{G} \times \mathrm{E}$ effect arises when an interaction occurs between the genotypes and the periods; in other words, genotypes perform differently in different periods. This phenomenon may result in the reranking of animals among different periods (Falconer, 1989). In such situation, periods with and without grazing may be treated as 2 separate environments. Genetic correlation between a trait measured in both environments may be treated as a measure of the $\mathrm{G} \times \mathrm{E}$ effect (Falconer, 1952). However, in the current study, no pedigree or genomic information was available. Therefore, we treated the individual-level correlations between environments $(\mathrm{P} \times \mathrm{E})$ as a phenotypelevel equivalent for $\mathrm{G} \times \mathrm{E}$ (genetic level).

Magnitude. The individual-level correlation between the 2 periods for all 3 traits indicates that both periods agreed well (0.97-0.99); however, the $\pm 1.96 \mathrm{SE}$ confidence interval did not reach 1.00 for daily averaged $\mathrm{CH}_{4}$ and $\mathrm{CO}_{2}$ concentrations. Thus, a slight reranking of animals between indoor feeding and grazing periods might arise. Possible reasons are changes in nutrition, maintenance, and activity during the animal's daily routine and the cows responding to these factors in different ways due to genetic differences. However, the correlation between the 2 periods was sufficiently high to limit the reranking of cow performance, and it indicates a weak $\mathrm{P} \times \mathrm{E}$ interaction between indoor feeding on TMR and outdoor grazing with TMR supplementation. Correlations between weeks showed differences between the ranking of cows for both periods visually. Weeks within each period formed 2 squares with high individual-level correlation. The individual-level correlations between these 2 squares were also high but lower than those within squares. Heatmaps show that grazing influenced the ranking of cows based on the $\mathrm{CH}_{4}$ and $\mathrm{CO}_{2}$ emissions as well as their ratio at least 4 wk after transition from the barn. Genetic correlations are required to validate the presence or absence of $\mathrm{G} \times$ E (Falconer, 1952). Running 2 separate, environmentspecific breeding programs would only result in higher genetic gain compared with a single evaluation for both environments if the genetic correlation between environments is lower than 0.6 to 0.8 . This threshold strongly depends on the selection intensity and importance of each environment (Mulder et al., 2006). The lack of a strong evidence for $\mathrm{P} \times \mathrm{E}$ from this study is similar to the results from studies about $\mathrm{G} \times \mathrm{E}$ in other traits and breeds. Grazing did not reveal strong $\mathrm{G} \times \mathrm{E}$ in production (e.g., Boettcher et al., 2003; Kearney et al., 2004b; van der Laak et al., 2016), reproductive (e.g., Boettcher et al., 2003; Kearney et al., 2004a), workability (e.g., van der Laak et al., 2016), or conformation (e.g., Boettcher et al., 2003; van der Laak et al., 2016) traits. A main reason why grazing cannot reveal strong $\mathrm{G} \times \mathrm{E}$ is that, even during grazing, a large proportion of DMI is derived from PMR (fed indoors), resulting in DMI being the same as it was during the indoor period.

\section{Repeatabilities}

Lassen and Løvendahl (2016) obtained higher repeatability for the $\mathrm{CH}_{4}: \mathrm{CO}_{2}$ ratio (0.35) compared with the bivariate repeatability obtained in our study (0.26). The study by Lassen and Løvendahl (2016) differed from the present study because (1) the authors used data averaged per milking, not per day; (2) data covered an entire year, which might have overshadowed variation across seasons; and (3) all farms included in the previous study only used an indoor feeding strategy. A full-year study on partially grazed animals is required, possibly from different breeds. A full year would cover all seasons and thus most combinations of pasture feed compositions. This approach would allow the amount of time that animals spend on the pasture to be quantified to understand how access to grazing influences $\mathrm{CH}_{4}$ and $\mathrm{CO}_{2}$ enteric emissions. Breeding values estimation is necessary to estimate shift in animals' rankings $(\mathrm{G} \times \mathrm{E})$ between gas concentrations measured under 2 different environments. To determine if a particular method of recording $\mathrm{CH}_{4}$ emission is suitable for accurate breeding values estimation, several genetic parameters (such as heritability, genetic variation, and genetic correlations) must be assessed under the relevant conditions with sufficiently large cohorts of cows and repeated measures (de Haas et al., 2016). However, we did not have 
access to pedigrees or genotypes; therefore, we were limited to technical parameters, that is, repeatability and individual-level correlations between gas measurements and periods. Thus, further studies are required, especially on genetic correlations between enteric GHG emission from both environments.

\section{CONCLUSIONS}

We obtained a very high correlation between indoor and grazing periods for $\mathrm{CH}_{4}$ and $\mathrm{CO}_{2}$ concentrations and their ratio; however, we found that some minor reranking among random animal solutions is possible. This result indicates the possibility of a weak $\mathrm{P} \times \mathrm{E}$ effect over the periods examined. Based on the available data, we found no strong evidence supporting the need to separate the evaluation for enteric GHG emissions from dairy cattle between indoor and grazing periods. Further research of more herds and genetic analyses are needed over longer periods to estimate the effects of grazing on $\mathrm{CH}_{4}$ emission traits from dairy cows.

\section{ACKNOWLEDGMENTS}

The study was financed by the project "REFFICO - Robust and Efficient dairy cows" from the GUDP "Green Development and Demonstration Programme" project number 34009-14-0848, Danish Ministry of Environment and Food. The authors thank M. Bjerring (Aarhus University) for assistance on the installation and maintenance of instruments. The authors thank the commercial herd for providing access to cows and data for this study. The authors are grateful to the EU COST-action METHAGENE network for interesting discussions and input.

\section{REFERENCES}

Adolph, S. C., and J. S. Hardin. 2007. Estimating phenotypic correlations: Correcting for bias due to intraindividual variability. Funct. Ecol. 21:178-184.

Aguerre, M. J., M. A. Wattiaux, J. M. Powell, G. A. Broderick, and C. Arndt. 2011. Effect of forage-to-concentrate ratio in dairy cow diets on emission of methane, carbon dioxide, and ammonia, lactation performance, and manure excretion. J. Dairy Sci. 94:3081-3093.

Bakdash, J. Z., and L. R. Marusich. 2017. Repeated measures correlation. Front. Psychol. 8:456.

Bell, M. J., N. Saunders, R. H. Wilcox, E. M. Homer, J. R. Goodman, J. Craigon, and P. C. Garnsworthy. 2014. Methane emissions among individual dairy cows during milking quantified by eructation peaks or ratio with carbon dioxide. J. Dairy Sci. 97:6536-6546.

Bijma, P., and J. W. M. Bastiaansen. 2014. Standard error of the genetic correlation: How much data do we need to estimate a purebred-crossbred genetic correlation? Genet. Sel. Evol. 46:79.

Boettcher, P. J., J. Fatehi, and M. M. Schutz. 2003. Genotype $\times$ environment interactions in conventional versus pasture-based dairies in Canada. J. Dairy Sci. 86:383-389. de Haas, Y., P. C. Garnsworthy, B. Kuhla, E. Negussie, M. Pszczola, E. Wall, and J. Lassen. 2016. Genetic control of greenhouse gas emissions. Adv. Anim. Biosci. 7:196-199.

de Haas, Y., M. Pszczola, H. Soyeurt, E. Wall, and J. Lassen. 2017. Invited review: Phenotypes to genetically reduce greenhouse gas emissions in dairying. J. Dairy Sci. 100:855-870.

Difford, G. F., J. Lassen, and P. Løvendahl. 2016. Interchangeability between methane measurements in dairy cows assessed by comparing precision and agreement of two non-invasive infrared methods. Comput. Electron. Agric. 124:220-226.

Dijkstra, J., J. L. Ellis, E. Kebreab, A. B. Strathe, S. López, J. France, and A. Bannink. 2012. Ruminal pH regulation and nutritional consequences of low pH. Anim. Feed Sci. Technol. 172:22-33.

Dingemanse, N. J., and N. A. Dochtermann. 2013. Quantifying individual variation in behaviour: Mixed- effect modelling approaches. J. Anim. Ecol. 82:39-54.

Eckert, M., M. Bell, S. Potterton, J. Craigon, N. Saunders, R. Wilcox, M. Hunter, J. Goodman, and P. Garnsworthy. 2018. Effect of feeding system on enteric methane emissions from individual dairy cows on commercial farms. Land (Basel) 7:1-9.

Ellis, J. L., J. Dijkstra, J. France, A. J. Parsons, G. R. Edwards, S. Rasmussen, E. Kebreab, and A. Bannink. 2012. Effect of highsugar grasses on methane emissions simulated using a dynamic model. J. Dairy Sci. 95:272-285.

Falconer, D., and T. Mackay. 1996. Introduction to Quantitative Genetics. 4th ed. Pearson, Upper Saddle River, NJ.

Falconer, D. S. 1952. The problem of environment and selection. Am. Nat. 86:293-298.

Falconer, D. S. 1989. Introduction to Quantitative Genetics. 3rd ed. Longman Group, Essex, UK.

FAO. 2018. FAOSTAT: Online Statistical Database. Accessed May 1, 2018. http://faostat.fao.org.

Garnsworthy, P. C., J. Craigon, J. H. Hernandez-Medrano, and N. Saunders. 2012. On-farm methane measurements during milking correlate with total methane production by individual dairy cows. J. Dairy Sci. 95:3166-3180.

Hammond, K. J., L. A. Crompton, A. Bannink, J. Dijkstra, D. R. Yáñez-Ruiz, P. O'Kiely, E. Kebreab, M. A. Eugene, Z. Yu, K. J. Shingfield, A. Schwarm, and A. N. Hristov. 2016a. Review of current in vivo measurement techniques for quantifying enteric methane emission from ruminants. Anim. Feed Sci. Technol. 219:13-30.

Hammond, K. J., D. J. Humphries, L. A. Crompton, C. Green, and C. K. Reynolds. 2015. Methane emissions from cattle: Estimates from short-term measurements using a GreenFeed system compared with measurements obtained using respiration chambers or sulphur hexafluoride tracer. Anim. Feed Sci. Technol. 203:41-52.

Hammond, K. J., A. K. Jones, D. J. Humphries, L. A. Crompton, and C. K. Reynolds. 2016b. Effects of diet forage source and neutral detergent fiber content on milk production of dairy cattle and methane emissions determined using GreenFeed and respiration chamber techniques. J. Dairy Sci. 99:7904-7917.

ISO (International Organization for Standardization). 2004. ISO 8601:2004. Data elements and interchange formats - Information interchange - Representation of dates and times. https://www.iso .org/standard/40874.html.

Kearney, J. F., M. M. Schutz, and P. J. Boettcher. 2004a. Genotype $\times$ environment interaction for grazing vs. confinement. II. Health and reproduction traits. J. Dairy Sci. 87:510-516.

Kearney, J. F., M. M. Schutz, P. J. Boettcher, and K. A. Weigel. 2004b. Genotype $\times$ environment interaction for grazing versus confinement. I. Production traits. J. Dairy Sci. 87:501-509.

Lassen, J., and P. Løvendahl. 2016. Heritability estimates for enteric methane emissions from Holstein cattle measured using noninvasive methods. J. Dairy Sci. 99:1959-1967.

Lassen, J., P. Løvendahl, and J. Madsen. 2012. Accuracy of noninvasive breath methane measurements using Fourier transform infrared methods on individual cows. J. Dairy Sci. 95:890-898.

Løvendahl, P., and M. A. Bjerring. 2006. Detection of carryover in automated milk sampling equipment. J. Dairy Sci. 89:3645-3652.

Madsen, J., B. S. Bjerg, T. Hvelplund, M. R. Weisbjerg, and P. Lund. 2010. Methane and carbon dioxide ratio in excreted air for quanti- 
fication of methane production in ruminants. Livest. Sci. 129:223227.

Madsen, P., and J. Jensen. 2013. A User's Guide to DMU. A Package for Analysing Multivariate Mixed Models. Center for Quantitative Genetics and Genomics, Department of Molecular Biology and Genetics, University of Aarhus Research Centre, Tjele, Denmark.

Mulder, H. A., R. F. Veerkamp, B. J. Ducro, J. A. M. Van Arendonk, and P. Bijma. 2006. Optimization of dairy cattle breeding programs for different environments with genotype by environment interaction. J. Dairy Sci. 89:1740-1752.

Münger, A., and M. Kreuzer. 2008. Absence of persistent methane emission differences in three breeds of dairy cows. Aust. J. Exp. Agric. 48:77-82.

Pszczola, M., K. Rzewuska, S. Mucha, and T. Strabel. 2017. Heritability of methane emissions from dairy cows over a lactation measured on commercial farms. J. Anim. Sci. 95:4813-4819.

R Development Core Team. 2008. R: A language and environment for statistical computing. R Foundation for Statistical Computing, Vienna, Austria. http://www.R-project.org.

Robertson, L., and G. Waghorn. 2002. Dairy industry perspectives of methane emissions and production from cattle fed pasture or total mixed rations in New Zealand. Pages 213-218 in Proceedings of the New Zealand Society of Animal Production, Palmerston North, New Zealand.
Steinfeld, H., P. Gerber, T. Wassenaar, V. Castel, M. Rosales, and C. de Haan. 2006. Livestock's Long Shadow. FAO, Rome, Italy.

van der Laak, M., M. L. van Pelt, G. De Jong, and H. A. Mulder. 2016. Genotype by environment interaction for production, somatic cell score, workability, and conformation traits in Dutch Holstein-Friesian cows between farms with or without grazing. J. Dairy Sci. 99:4496-4503.

van Engelen, S., H. Bovenhuis, P. P. J. van der Tol, and M. H. P. W. Visker. 2018. Genetic background of methane emission by Dutch Holstein Friesian cows measured with infrared sensors in automatic milking systems. J. Dairy Sci. 101:2226-2234.

Wilmink, J. B. M. 1987. Adjustment of test-day milk, fat and protein yield for age, season and stage of lactation. Livest. Prod. Sci. $16: 335-348$

Wu, L., P. W. G. G. Koerkamp, and N. Ogink. 2018. Uncertainty assessment of the breath methane concentration method to determine methane production of dairy cows. J. Dairy Sci. 101:15541564.

Zetouni, L., M. Kargo, E. Norberg, and J. Lassen. 2018. Genetic correlations between methane production and fertility, health, and body type traits in Danish Holstein cows. J. Dairy Sci. 101:2273-2280. 